\title{
Clinical utility and patient adherence with ebastine for allergic rhinitis
}

\author{
This article was published in the following Dove Press journal: \\ Patient Preference and Adherence \\ 13 October 2010 \\ Number of times this article has been viewed
}

\section{Giorgio Ciprandi \\ Department of Internal Medicine, San Martino Hospital, Genoa, Italy}

Correspondence: Giorgio Ciprandi Semeiotica e Metodologia Medica I,Viale Benedetto XV 6, 16132 Genoa, Italy $\mathrm{Tel}+39103533 \quad 1820$

Fax+39103537573

Email gio.cip@libero.it
Abstract: Allergic rhinitis (AR) is a high prevalence disease, affecting 10\%-20\% of the general population. AR is sustained by an IgE-mediated reaction, and by a complex inflammatory network of cells, mediators, and cytokines, becoming chronic when exposure to allergen persists. A Th2-biased immune response is the basis for the allergic inflammation. Histamine plays a relevant role in symptom occurrence. Therefore, antihistamine use represents a cornerstone in AR management. Ebastine, a novel antihistamine, is effective overall in controlling symptoms, and its safety profile is good. Recently, a new formulation has been developed, ie, a fast-dissolving tablet. Several studies have demonstrated its favorable characteristics. In conclusion, ebastine is an effective and well tolerated antihistamine that may be prescribed for the treatment of AR. The fast-dissolving tablet formulation provides a new option which may be particularly convenient for the patient.

Keywords: allergic rhinitis, histamine, antihistamines, ebastine, tablets

\section{Introduction}

Allergic rhinitis (AR) is the most common immune-mediated disease. AR is defined as a symptomatic disease of the nasal mucosa following an IgE-mediated reaction. ${ }^{1}$ Numerous questionnaire-based surveys performed in the last decade report that the prevalence ranges between $10 \%$ and $20 \%$ (widely variable between different countries) and can be as high as $25 \%$ in adolescents. ${ }^{2-4}$ Although AR is not a life-threatening condition, it has been documented to have a significant impact on quality of life and is associated with significant costs..$^{5-7}$ Moreover, AR is often associated with asthma, and is a risk factor for asthma onset and worsening. ${ }^{1}$ Thus, optimal treatment of AR would lead to improved quality of life, reduced occurrence of comorbidities, and better control of asthma, with relevant socioeconomic implications. Presently, there are a number of effective therapeutic pharmacologic options available, but the general belief is that treatment can be improved upon by ameliorating patient adherence, the safety profile of existing drugs, or modifying the immune response in the early stages.

From a pathophysiologic point of view, AR is characterized essentially by an inflammatory process (allergic inflammation) that starts with IgE-dependent mast cell degranulation. Histamine is the main mediator of the early phase, and is responsible for the typical symptoms of sneezing, itching, rhinorrhea, and nasal obstruction. ${ }^{8}$ Upon activation, mast cells trigger synthesis of other inflammatory mediators, including leukotrienes and prostaglandins, and secretion of cytokines. Thus, the immediate phase is followed by delayed infiltration of the nasal mucosa by leukocytes, mainly 
eosinophils, ${ }^{9}$ that are considered the hallmark of allergic inflammation. ${ }^{10}$ The selective accumulation of inflammatory cells at the nasal level is orchestrated by the adhesion machinery. Obviously, the recruited inflammatory cells are also important sources of mediators and cytokines that maintain, amplify, and enhance allergic inflammation.

T-cells are pivotal in the inflammation associated with allergy, but also are responsible of the development of the so-called allergic phenotype. In fact, allergic subjects have an imbalance between the two subsets of TCD4+, ie, Th1 and Th2, in favor of the Th2 phenotype. Indeed, Th1 cells are responsible for the usual host defense against bacterial and viral pathogens, whereas Th2 cells produce the cytokines, ie, interleukin (IL)-3, IL-4, IL-5, and IL-13, that are involved in IgE synthesis and in eosinophil and fibroblast activation. ${ }^{11,12}$ The balance between Th1 and Th2 cells is regulated by so-called regulatory cells. A defect in the activity of these regulatory cells can lead either to allergy or to autoimmune disease. ${ }^{13,14}$ Finally, it has been documented that a weak inflammatory infiltrate may be present in the nose, even in absence of symptoms, when a subthreshold exposure to the allergen persists (minimal persistent inflammation). ${ }^{15}$ Thus, the duration of exposure to allergen, rather than the type of allergen, is critical for allergic inflammation. For this reason, a new classification of AR has been recently proposed and validated, so the traditional terms "seasonal" and "perennial" have been replaced by "intermittent" and "persistent". Also, based on symptom impact on daily life, the severity has been graded as mild or moderate/severe. The treatment of AR has four components, ie, patient education, allergen avoidance, drug therapy, and specific immunotherapy.

\section{Allergen avoidance}

Unfortunately, meta-analyses of the studies dealing with allergen avoidance/control measures report only a marginal and inconsistent benefit. ${ }^{16}$ Indeed, it is clear that the available environmental interventions (high-efficiency particulate air filters, acaricides, impermeable bed covers, etc) are not sufficient if used alone to treat symptoms. Moreover, with outdoor allergens, such as pollens or molds, there is no feasible intervention. Nonetheless, reasonable avoidance measures are always recommended for allergic patients.

\section{Pharmacotherapy}

Drugs are prescribed according to the ARIA (Allergic Rhinitis and its Impact on Asthma) guidelines on the basis of frequency and severity of symptoms, in a stepwise manner (as made for asthma). Oral and topical second-generation $\mathrm{H}_{1}$ antihistamines (azelastine, cetirizine, desloratadine, ebastine, fexofenadine, levocabastine, levocetirizine, loratadine) are recommended in all steps of the disease due to their good risk:benefit ratio and the additional anti-inflammatory activities exerted by some molecules. ${ }^{17}$ Moreover, it has been suggested that long-term use of antihistamines is preferable to symptomatic therapy. ${ }^{18}$

Nasal glucocorticosteroids (beclomethasone, budesonide, ciclesonide, flunisolide, fluticasone, mometasone, triamcinolone) are the most efficacious medications available for the treatment of AR. Due to their broad anti-inflammatory action, they also control nasal obstruction well. Intranasal corticosteroids are generally well tolerated, despite some concerns about possible side effects. Therefore, caution is recommended when using long-term treatments, and especially when nasal steroids are used in association with inhaled steroids. ${ }^{19}$ Decongestants or vasoconstrictors have a rapid action on nasal congestion, but their long-term use is associated with atrophy of the nasal mucosa (rhinitis medicamentosa). Decongestants are indicated only for short courses of treatment, in association with other drugs. Other possible treatments include cromones, leukotriene modifiers (especially when asthma coexists), anticholinergics, and nasal lavage.

\section{Allergen-specific immunotherapy}

Allergen-specific immunotherapy (SIT) is the procedure of administering increasing amounts of the allergen(s) in order to achieve hyposensitization (ie, tolerance to the causal allergen), and thereby reduce symptoms (and need for relief medications) when exposure to the allergen occurs. Since its empiric introduction in 1911, SIT was administered by subcutaneous injection. This practice has been demonstrated to carry some risk for fatal or near-fatal adverse events, including asthma, angioedema, and anaphylaxis, ${ }^{20}$ so the more safe sublingual route was developed and validated. ${ }^{21}$ In recent years, the indications, contraindications, and precautions for giving SIT have been clearly stated in a World Health Organization (WHO) document, where it is emphasized that SIT is safe when correctly prescribed and administered, and when high-quality allergenic extracts are used.,22,23 The effects of SIT are both curative and preventive. SIT is able to reduce symptoms and the need for medications in asthma and rhinitis, maintains its clinical efficacy for years after discontinuation, prevents onset of new sensitizations, and prevents onset of asthma in patients with rhinitis alone. ${ }^{24,25}$ Thus, SIT is an allergen-oriented disease-modifying treatment, and has enormous potential for development. 


\section{Patient adherence}

AR is considered to be a chronic illness, therefore adherence to long-term therapy is important. In this regard, WHO defines treatment adherence as an individual behavior which consists of both compliance (ie, taking the prescribed drugs at the indicated dosage and with the suggested frequency) and persistence (ie, continuation of treatment for the recommended duration). ${ }^{26}$ A patients is considered "adherent to treatment" if he or she takes more than $80 \%$ of the prescribed drug. Several factors may significantly affect adherence to treatment, positively or negatively. Some of these factors depend on the particular characteristics of the patient or on their general socioeconomic context, whereas others depend on the prescribed drug and the schedule. Surveys of patient behavior show that in about $50 \%$ of cases the drug is not used as prescribed by the doctor. ${ }^{26} \mathrm{The}$ most frequent reason given by patients to justify their failed adherence is forgetfulness. A possible cause of this phenomenon may be the psychologic mechanism of negation, eg, the negation of the illness and of factors related to the treatment. Other factors involved in impaired adherence may include cost, difficulty of use, manageability, tolerability, and safety. On the other hand, it has been reported that patients are well motivated to adhere to a treatment when they understand and accept the diagnosis, agree with the doctor about treatment, and are able to discuss their concerns about the treatment with the doctor. The WHO document suggests that simplification of treatment may be an effective strategy for improving adherence. ${ }^{26}$ Moreover, pharmaceutical manufacturers may enhance adherence by developing drugs which are effective, easy to use, and well tolerated. Another important issue is the information provided for physicians and patients, as well as reinforcement of the therapeutic alliance between all people involved in the therapeutic pathway. In this regard, the treatment of AR is based on the prescription of antihistamines first-line, mainly the second-generation agents. ${ }^{27}$ In fact, second-generation antihistamines are characterized by good efficacy and an optimal safety profile. Both doctors and patients maintain that effectiveness (including early activity and prolonged effect), safety, easy of use, and once-daily administration are relevant factors for enhancing treatment adherence. Ebastine is a second-generation antihistamine with good efficacy and is well tolerated, for which a new formulation has recently been devised, ie, a fast-dissolving tablet (FDT), characterized by rapid disintegration in the mouth.

\section{Pharmacology of ebastine}

Ebastine is a second-generation $\mathrm{H}_{1}$-receptor antagonist with an oxypiperidine-based structure, the active form of which is the metabolite, carebastine. ${ }^{28}$ Ebastine is administered orally once daily, and is indicated for treatment of symptoms of allergic rhinitis and chronic idiopathic urticaria, and in some countries, for relief from mosquito bites or atopic dermatitis.

Ebastine is rapidly absorbed after oral administration, but undergoes extensive first-pass metabolism to its active metabolite. ${ }^{29}$ Steady-state concentrations are achieved after four days of administration, and food intake does not affect the pharmacokinetics. Carebastine is mainly excreted in the urine. The pharmacokinetics are also unaffected by gender, but are affected by age, in that elderly patients show a shorter time to peak concentration than younger patients. The presence of mild to severe renal or hepatic impairment does not alter the pharmacokinetics of carebastine to a clinically significant extent. There is a drug interaction with ketoconazole and erythromycin, in that both drugs increase the peak concentration.

With regard to its pharmacodynamic properties, ebastine at doses $\geq 10 \mathrm{mg}$ significantly reduces the histamine-induced cutaneous wheal response. Overall, ebastine $10 \mathrm{mg}$ has been shown to be as effective at inhibiting the histamine-induced wheal response as several other antihistamines, including loratadine, cetirizine, fexofenadine, and mizolastine. ${ }^{30}$ Ebastine $10 \mathrm{mg}$ and $30 \mathrm{mg}$ significantly protect against histamine-induced bronchoconstriction compared with placebo in asthmatic patients.

The antiallergic effects of ebastine have been assessed by cutaneous and nasal challenge with allergens, and by measurement of inflammatory mediators. Ebastine $20 \mathrm{mg}$ significantly reduced both wheal and flare responses to allergens. In addition, a single dose of ebastine $10 \mathrm{mg}$ reduced the diameter of grass pollen-induced wheal. Ebastine also reduced the nasal symptoms occurring after nasal provocation with grass pollen.

In addition to blocking the $\mathrm{H}_{1}$-receptor, an antihistamine may have other effects that contribute to its antiallergic effect. Consequently, the effect of ebastine on various mediators of inflammation has been investigated. In vitro ebastine inhibits anti-IgE-induced release of prostaglandins and leukotrienes by nasal polyp cells and cytokines, including granulocyte-macrophage colony-stimulating factor (GM-CSF), tumor necrosis factor, and IL-8. Ebastine also reduces the release of GM-CSF in nasal secretions, nasal eosinophilia (assessed using nasal smears), serum eosinophil cationic protein levels, and peripheral blood eosinophil count.

In conclusion, maximum plasma concentrations are achieved 4-6 hours after dosing, and steady state is reached 
after four days. Ebastine can be administered once daily, with or without food. Dose modifications are not needed in elderly patients, or in those with renal or mild-moderate hepatic impairment. Coadministration with ketoconazole or erythromycin increases plasma levels, but without clinical consequences. Ebastine produces a dose-dependent inhibition of the cutaneous reaction to histamine, increases the threshold quantity of pollen required to induce an allergic reaction in nasal challenge, and the antihistaminic effect lasts for more than 48 hours.

\section{Efficacy}

The efficacy of once-daily oral ebastine in the management of allergic rhinitis has been evaluated in a number of well designed clinical trials in adults and adolescents. Most of these trials were randomized, double-blind, and placebo- or active-controlled. Almost all major studies with the regular formulation of ebastine were performed before the current ARIA classification of the intermittent and persistent forms of allergic rhinitis. Patients were considered in those studies as suffering from seasonal or perennial AR. In addition, patient preference trials with the FDT formulation used the ARIA classification. In most trials, the evaluation of efficacy was on the basis of an assessment of nasal symptoms (rhinorrhea, sneezing, itching, and obstruction) and ocular symptoms (itch, tearing, hyperemia), using a four-point scale, ie, $0=$ absent, $1=$ mild, $2=$ moderate, $3=$ severe. The studies are very synthetically reported, referring to a very recent exhaustive review. ${ }^{30}$

\section{Seasonal allergic rhinitis}

There are eight studies which showed that ebastine was significantly more effective than placebo at relieving symptoms of seasonal AR. ${ }^{31-38}$ Overall, most trials reported that doses of $10 \mathrm{mg}$ and $20 \mathrm{mg}$ once daily were more effective than placebo. In terms of the patient's global evaluation of efficacy, ebastine $20 \mathrm{mg}$ (but not $10 \mathrm{mg}$ ), whether used in the morning or afternoon, was rated significantly better than placebo. In comparison with other second-generation antihistamines, ebastine was as effective as cetirizine and at least as effective as loratadine. In addition, a meta-analysis reported that ebastine was more effective than loratadine. ${ }^{39}$ Interestingly, in one noncomparative study specifically evaluating nasal obstruction, ebastine was able to reduce this symptom in patients with pollen allergy. ${ }^{40}$

\section{Perennial allergic rhinitis}

Ebastine was significantly more effective than placebo at relieving most symptoms of perennial AR, as reported by four studies. ${ }^{41-44}$ Clinical efficacy was evaluated as good or very good by most patients.

\section{Persistent allergic rhinitis}

Only one study has been performed in patients with persistent allergic rhinitis. ${ }^{40}$ Treatment with ebastine significantly improved nasal symptoms and nasal airflow, as assessed by rhinomanometry. In addition, ebastine treatment significantly modified the response to the nasal decongestion test.

\section{Safety and tolerability}

Ebastine was generally well tolerated in clinical trials involving patients with allergic rhinitis. The incidence of adverse events was similar to that of placebo. Moreover, the active comparator trials showed that the incidence of adverse events with ebastine was similar to that with loratadine or cetirizine. In addition, the severity of these adverse events was mild or moderate in most cases.

The most common adverse events, recorded in trials concerning more than 3000 patients, were headache $(7.9 \%)$, drowsiness $(3 \%)$, and dry mouth $(2.1 \%)$. Two long-term studies of three to four months' duration showed good tolerability, with the most common adverse event reported being headache. ${ }^{34,35}$

Regarding cardiac safety, there is a possibility that some antihistamines, including terfenadine and astemizole, are associated with prolongation of the $\mathrm{QT}_{\mathrm{c}}$ interval and the consequent possible development of fatal arrhythmias, such as torsade de pointes. ${ }^{1}$ This phenomenon is related to blockade of the potassium channels involved in the cardiac repolarization phase by certain drugs, but not consequent to $\mathrm{H}_{1}$-block. Therefore, there is no class effect for antihistamines. The ebastine trials showed that doses of $10 \mathrm{mg}$ and $20 \mathrm{mg}$ have no clinically relevant effect on the QT ${ }_{c}$ interval. ${ }^{46}$ In addition, there were no problems with possible interaction with other drugs, such as erythromycin and ketoconazole.

With regard to central nervous system tolerability, it is well known that the second-generation antihistamines are generally less sedating than the first-generation ones. ${ }^{47}$ A risk:benefit ratio has been calculated on the basis of the number of psychomotor and cognitive tests impaired by a drug. Ebastine was one of the few antihistamines to produce no impairment in any test, and thus has a very favorable risk:benefit ratio for sedation. ${ }^{47}$

In conclusion, ebastine is generally well tolerated. The most common adverse events include headache, somnolence, and dry mouth. Coadministration with ketoconazole or erythromycin is not clinically relevant for cardiac adverse events. Ebastine $10 \mathrm{mg}$ and $20 \mathrm{mg}$ are not sedating, and do not impair cognitive or psychomotor performance, including driving ability. 


\section{Ebastine fast-dissolving tablets}

The FDT that has been developed is bioequivalent with the regular tablet form. This is a unique freeze-dried medicinal tablet that disintegrates immediately in the oral cavity. Pharmacokinetic bioequivalence between ebastine FDT and the regular tablet was demonstrated in healthy males, in whom the range for equivalence was $0.8-1.25 .^{48}$ Three preference studies have been conducted, ${ }^{49-51}$ and are discussed in the next section. There is only one experimental study conducted so far with FDT ebastine..$^{52}$ It explored the ability of ebastine to modulate interferon-gamma in patients with persistent allergic rhinitis. Ebastine FDT dissolves rapidly in the mouth and can be taken without the aid of a drink and is bioequivalent to the regular ebastine tablet.

\section{Patient-focused perspectives}

The new FDT formulation has been developed to improve satisfaction and treatment adherence in patients. In this regard, three studies have been conducted.

The first study evaluated the preferences of AR patients who were given either a placebo version of ebastine FDT or a placebo version of the ebastine regular tablet. ${ }^{49} \mathrm{AR}$ patients from Germany, Italy, and Mexico, who were regular consumers of oral antihistamines, were recruited for this randomized crossover study. Patients were interviewed at home by an interviewer using a computerassisted telephone interview technique, and the findings were analysed using descriptive statistics. A total of 420 patients participated (140 from each country), $70 \%$ with intermittent and 24\% with persistent AR. Ebastine FDT was significantly better than the regular tablet for sensation of dissolving, taste left in the mouth, initial taste, and texture. Overall, $83 \%$ of patients preferred ebastine FDT to the regular tablet.

The second study evaluated patient perception of the onset of action and overall satisfaction with ebastine FDT in 100 patients with intermittent and persistent $\mathrm{AR} .{ }^{50}$ This was a cross-sectional, multicenter, pharmacy-based survey involving adult patients. Via a telephone interview, patients were asked to evaluate the characteristics of ebastine FDT in comparison with their previous experience of other antihistamines. Patients rated ebastine very highly (mean scores were 4.5-4.7 out of a possible 5) for onset of action, with high statistical significance $(P<0.001)$. A total of $85 \%$ of patients perceived the onset of action of ebastine FDT to be fast or very fast, and $77 \%$ indicated that it acted faster than their usual antihistamine. A total of $96 \%$ were satisfied or very satisfied with ebastine FDT, 98\% were interested in using the drug again, and FDT was significantly better appreciated than the regular tablets $(P<0.001)$.

The third study assessed patient satisfaction with ebastine FDT using the Treatment Satisfaction Questionnaire for Medication. ${ }^{51}$ This was an international, multicenter, observational study involving 461 patients with intermittent or persistent AR who had received a prescription for ebastine FDT $20 \mathrm{mg}$ in the previous two months. The overall ratings for effectiveness, side effects, convenience, and global satisfaction were high for ebastine FDT. A total of $79 \%$ of patients reported a fast or very fast onset of action. On the last day of treatment, patients reported a significant improvement in the intensity and relief of AR symptoms. Ninety-five percent of patients reported good or very good tolerability with ebastine FDT. Compared with the patient's experience of previous therapy, ebastine FDT was considered better or much better for efficacy ( $81 \%$ ), tolerability $(73 \%)$, onset of action (79\%), and convenience $(94 \%, P<0.001)$.

These three studies demonstrate that ebastine FDT is associated with a very high satisfaction rate and significant relief of AR symptoms, and, consequently, patients reported a preference for the FDT formulation over previous antihistamines that they had used.

In conclusion, patients find ebastine FDT convenient and easy to use, perceive it to have a rapid onset of action, and report high levels of satisfaction with treatment. In addition, ebastine FDT may be useful for patients with swallowing difficulties, gastrointestinal problems, or a particularly active lifestyle.

\section{Conclusion}

Histamine plays a significant pathogenic role in AR, thus the use of antihistamines is a cornerstone of treatment. ${ }^{53}$ In this regard, second-generation antihistamines should be prescribed as firstline treatment. Ebastine has a good efficacy and safety profile. In addition, the new FDT formulation meets patients' needs, in that it has the same efficacy and safety profile as the regular tablets, is easy to use, portable, and is perceived as having a rapid onset of action. All these issues improve treatment compliance and consequently AR management. Therefore, ebastine FDT should be used for its convenience and adherence profile, although it should not be used if ineffective in a particular patient. In terms of cost, ebastine FDT is approximately the same price as the regular tablets, and their cost is comparable with that of other antihistamines in the European Community.

\section{Disclosure}

The author reports no conflict of interest in this work. 


\section{References}

1. Bousquet J, van de Cauwenberge P. Allergic Rhinitis and its Impact on Asthma (ARIA) WHO position paper. J Allergy Clin Immunol. 2001;108:S147-S334.

2. Bjorksten B, Brunekreef B, Cookson WO, von Mutius E, Strachan DP. Phase II of the International Study of Asthma and Allergies in Childhood (ISAAC II): Rationale and methods. Eur Respir J. 2004;24:406-412.

3. Bugiani A, Carosso A, Migliore E, et al. Allergic rhinitis and asthma comorbidity in a survey of young adults in Italy. Allergy. 2005;60:165-170.

4. Turkeltaub PC. Prevalence of upper and lower respiratory conditions in the US population by social and environmental factors: Data from the second National Health and Nutrition Examination Survey, 1976 to 1980 (NHANES II). Ann Allergy. 1991;67:147-154.

5. Meltzer EO. Quality of life in adults and children with allergic rhinitis. J Allergy Clin Immunol. 2001;108:S45-S53.

6. Schoenwetter WF, Dupclay L Jr, Appajosyula S, Botteman MF, Pashos CL. Economic impact and quality-of-life burden of allergic rhinitis. Curr Med Res Opin. 2004;20:305-317.

7. Tripathi A, Patterson R. Impact of allergic rhinitis treatment on quality of life. Pharmacoeconomics. 2001;19:891-899.

8. Pawankar R, Yamagishi S, Takizawa R, Yagi T. Mast cell-IgE-and mast cell-structural cell interactions in allergic airway disease. Curr Drug Targets Inflamm Allergy. 2003;2:303-312.

9. Allergy and allergic diseases. N Engl J Med. 2001;344:109-113.

10. Ciprandi G, Vizzaccaro A, Cirillo I, Tosca M, Massolo A, Passalacqua G. Nasal eosinophils display the best correlation with symptoms, pulmonary function and inflammation in allergic rhinitis. Int Arch Allergy Immunol. 2005;136:266-272.

11. Romagnani S. The Th1/Th2 paradigm. Immunol Today. 1997;18: 263-266.

12. Romagnani S. The role of lymphocytes in allergic disease. J Allergy Clin Immunol. 2000;105:399-408.

13. Romagnani S. Regulatory T cells: Which role in the pathogenesis and treatment of allergic disorders? Allergy. 2006;61:3-14.

14. Taylor A, Verhagen J, Akdis CA, Akdis M. T regulatory cells in allergy and health: A question of allergen specificity and balance. Int Arch Allergy Immunol. 2004;135:73-82.

15. Ciprandi G, Buscaglia S, Pesce GP, et al. Minimal persistent inflammation is present at mucosal level in asymptomatic rhinitic patients with allergy due to mites. J Allergy Clin Immunol. 1995;96:971-997.

16. Custovic A, van Wjik G. The effectiveness of measures to change the indoor environment in the treatment of allergic rhinitis and asthma: ARIA update (in collaboration with GA(2)LEN). Allergy. 2005;60:1112-1115.

17. Simons FER. Advances in H1-antihistamines. $N$ Engl J Med. 2004;351:2203-2217.

18. Ciprandi G, Ricca V, Tosca M, et al. Continuous antihistamine treatment controls allergic inflammation and reduces respiratory morbidity in children with mite allergy. Allergy. 1999;54:358-365.

19. Passalacqua G, Albano M, Canonica GW, et al. Inhaled and nasal corticosteroids: Safety aspects. Allergy. 2000;55:16-33.

20. Lockey RF, Nikoara-Kasti GL, Theodoropoulos DS, Bukantz SC. Systemic reactions and fatalities associated with allergen immunotherapy. Ann Allergy Asthma Immunol. 2001;87:S46-S55.

21. Cox L, Larenas D, Nolte H, Weldon D, Finegold I. Sublingual immunotherapy: A comprehensive review. J Allergy Clin Immunol. 2006;117:1021-1035.

22. World Health Organization Position Paper. Allergen immunotherapy: Therapeutic vaccines for allergic diseases. In: Bousquet J, Lockey R, Malling HJ, editors. Allergy. 1998:53:3-13.

23. Malling HJ, Abreu-Noguera J, Alvarez-Cuesta E, et al. Local immunotherapy: Position paper. Allergy. 1998;53:833-844.

24. Moller C, Dreborg S, Ferdousi HA, et al. Pollen immunotherapy reduces the development of asthma in children with seasonal rhinoconjunctivitis (the PAT study). J Allergy Clin Immunol. 2002;109:251-256.
25. Novembre E, Galli E, Landi F, et al. Coseasonal sublingual immunotherapy reduces the development of asthma in children with allergic rhinoconjunctivitis. J Allergy Clin Immunol. 2004;114:851.

26. World Health Organization. Adherence to long-term therapies: Evidence for action. Geneva: World Health Organization; 2003.

27. Bousquet J, Reid J, van Weel C, et al. Allergic rhinitis management pocket reference 2008. Allergy. 2008;63:990-996.

28. Roberts DJ. A preclinical overview of ebastine. Drugs. 1996;52:8-14.

29. Vincent J, Liminana R, Meredith PA, Reid JL. The pharmacokinetics, antithistamine and concentration-effect relationship of ebastine in healthy subjects. Br J Clin Pharmacol. 1988;26:497-502.

30. Sastre J. Ebastine in allergic rhinitis and chronic urticaria. Allergy. 2008:63:1-20.

31. Ankier SI, Warrington SJ. A double-blind placebo-controlled study of the efficacy and tolerability of ebastine against hayfever in general practice. J Intern Med. 1989;226:453-458.

32. de Molina M, Cadahia A, Cano L, Sanz A. Efficacy and tolerability of ebastine at two dose levels in the treatment of seasonal allergic rhinitis. Drug Invest. 1989;1:40-46.

33. Pelaez A. Clinical efficacy of ebastine in the treatment and prevention of seasonal allergic rhinitis. Drugs. 1996;52:35-38.

34. Storms WW. Clinical studies of the efficacy and tolerability of ebastine $10 \mathrm{mg}$ or $20 \mathrm{mg}$ once daily in the treatment of seasonal allergic rhinitis in the US. Drugs. 1996;52:20-25.

35. Gehanno P, Bremard-Oury C, Zeisser P. Comparison of ebastine cetirizine in seasonal allergic rhintis in adults. Ann Allergy Asthma Immunol. 1996;76:507-512.

36. Hampel F, Howland W, van Bavel J, Ratner P. A randomized doubleblind placebo-controlled study comparing the efficacy and safety of ebastine $(20 \mathrm{mg}$ and $10 \mathrm{mg}$ ) to loratadine $10 \mathrm{mg}$ once daily in the treatment of seasonal allergic rhinitis. J Investig Allergol Clin Immunol. 2004;14:56-63.

37. Ratner P, Hampel F, van Bavel J, Howland W. Efficacy and safety of ebastine $20 \mathrm{mg}$ compared to loratadine $10 \mathrm{mg}$ once daily in the treatment of seasonal allergic rhinitis: A randomized double-blind placebocontrolled study. Int Arch Allergy Immunol. 2004;133:371-379.

38. Ratner PH, Lim JC, Georges GC, Ebastine Study Group. Comparison of once-daily ebastine $20 \mathrm{mg}$, ebastine $10 \mathrm{mg}$, loratadine $10 \mathrm{mg}$, and placebo in the treatment of seasonal allergic rhinitis. J Allergy Clin Immunol. 2000;105:1101-1107.

39. Ratner P, Falques M, Chuecos F, Esbri R, Gispert J, Peris F. Meta-analysis of the efficacy of ebastine $20 \mathrm{mg}$ compared to loratadine $10 \mathrm{mg}$ and placebo in the symptomatic treatment of seasonal allergic rhinitis. Int Arch Allergy Immunol. 2005;138:312-318.

40. Ciprandi G, Cirillo I, Mora F, La Rosa M. Ebastine improves nasal symptoms and airflow and affects response to decongestion test in patient with persistent allergic rhinitis. Allergy Asthma Proc. 2007;28:578-581

41. Bousquet J, Gaudano EM, Palma Carlos AG, Staudinger H. A 12-week placebo-controlled study of the efficacy and safety of ebastine 10 and $20 \mathrm{mg}$ once daily in the treatment of perennial allergic rhinitis. Allergy. 1999;54:562-568.

42. Picado-Valles C, Cadahia-Garcia A, Bahima C, et al. Ebastine in perennial allergic rhinitis. Ann Allergy. 1991;67:615-618.

43. Davies RJ. European Multicentre Study Group. Efficacy and tolerability comparison of ebastine 10 and $10 \mathrm{mg}$ with loratadine $10 \mathrm{mg}$. Clin Drug Invest. 1998;16:413-420.

44. Murris-Espin M, Melac M, Charpentier JC, Didier A. Comparison of efficacy and safety of cetirizine and ebastine in patients with perennial allergic rhinitis. Ann Allergy Asthma Immunol. 1998;80:399-403.

45. Kalis B. Double-blind multicenter comparative study of ebastine, terfenadine and placebo in the treatment of chronic idiopathic urticaria in adults. Drugs. 1996;52:30-34.

46. Moss AJ, Chaikin P, Garcia JD, Gillen M, Roberts DJ, Morganroth J. A review of the cardiac systemic side-effects of antihistamines: Ebastine. Clin Exp Allergy. 1999;29:200-205. 
47. Hindmarch I, Shamzi Z. Antihistamines: Models to assess sedative properties, assessment of sedation, safety and other side-effects. Clin Exp Allergy. 1999;29:133-142.

48. Salvà M, Carreno B, Pintos M, Jansat JM, Rosales MJ, Megard Y. Phase I, single dose, open-label, randomized, cross-over bio-equivalence studies of ebastine $10 \mathrm{mg}$ and $20 \mathrm{mg}$ fast-dissolving tablets in healthy male volunteers. J Invest Allergol Clin Immunol. 2004;14:S5.

49. Roger A, Fortea J, Mora S, Artes M. Patient assessment of onset of action and overall satisfaction with ebastine fast-dissolving tablets in allergic rhinitis. Expert Rev Pharmacoecon Outcomes Res. 2008;8:337-342.

50. Roger A, Fortea J, Mora S, Artes M. Ebasstine fast-dissolving tablets versus regular tablets: Acceptability and preference in patients with allergic rhinitis. Expert Rev Clin Pharmacol. 2008;1:381-389.
51. Roger A, Fortea J, Plazas MJ, Mora S, Artes M. Assessment of patient satisfaction with ebastine fast-dissolving tablets in patients suffering from allergic rhinitis. Therapy. 2009;6:407-415.

52. Ciprandi G, Cirillo I, Pistorio A, di Gioacchino M, Fenoglio D. Ebastine increases IFN-gamma in patients with persistent allergic rhinitis. $J$ Bio Regul Homeost Agents. 2009;23:31-36.

53. Bousquet J, van Cauwenberge P, Bachert C, Canonica GW, Demoly P, Durham R. Requirement for medications commonly used in the treatment of allergic rhinitis. Allergy. 2003;58:192-197.

\section{Publish your work in this journal}

Patient Preference and Adherence is an international, peer-reviewed, open access journal focusing on the growing importance of patient preference and adherence throughout the therapeutic continuum. Patient satisfaction, acceptability, quality of life, compliance, persistence and their role in developing new therapeutic modalities and compounds to optimize clinical outcomes for existing disease states are major areas of interest. This journal has been accepted for indexing on PubMed Central. The manuscript management system is completely online and includes a very quick and fair peer-review system. Visit http://www.dovepress.com/ testimonials.php to read real quotes from published authors.

Submit your manuscript here: http://www.dovepress.com/patient-preference-and-adherence-journal 